\title{
THE IMPACT OF TROPOSPHERIC MAPPING FUNCTION ON PPP DETERMINATION FOR ONE-MONTH PERIOD
}

\author{
Sorin NISTOR *, Norbert-Szabolcs SUBA and Aurelian-Stelian BUDA
}

Department of Cadastre, University of Oradea, Oradea, Romania

*Corresponding author's e-mail: sonistor@uoradea.ro

\begin{tabular}{l} 
ARTICLE INFO \\
\hline Article history: \\
Received 3 February 2020 \\
Accepted 15 June 2020 \\
Available online 24 June 2020
\end{tabular}

Keywords:

PPP

Mapping function

Postfit residuals

Standard deviation

GNSS

Repeatability

\begin{abstract}
When using the PPP method, it is recommended to take into account the tropospheric influences for obtaining reliable estimates. Global Navigation Satellite System (GNSS) observations taken at low elevation suffer more strongly from atmospheric, antenna phase center variation and multipath effects, hence the observations are noisier than those at higher elevation angle, but they are essential to decorrelate the estimated station height and tropospheric zenith delay (ZTD). To relate the ZTD in the direction of an observation, the so-called mapping function (MF) are used. In this article the influence of different mapping function was studieds such as: Niell mapping function (NMF), Global Mapping Function (GMF) in conjunction with the Global Pressure and Temperature 2 -GPT2, Vienna Mapping Function 1 and no mapping function. The MF were used at different elevation cutoff angles $-5^{0}, 7^{0}, 10^{\circ}$ and $15^{\circ}$. The impact was analyzed: a) on the postfit residuals of the ionospheric free combination for phase (LC) and for pseudorange (PC), b) daily variability for North, East and Up component; c) evaluation of coordinates repeatability and how they are affected by the changes of the cutoff elevation angle and mapping function.

The analyzed data was taken from 4 EUREF stations for a period of one month - October 2015. By using the VMF1 mapping function, the lowest value was obtained for the postfit residuals of the LC combination for all the stations. The difference in daily variation between each individual solution for the horizontal component is at the level of $\sim 0.3 \div 0.5 \mathrm{~mm}$, with smaller effect on the East component compared to North, whereas the Up component is at the level of $\sim 1.0 \div 1.5 \mathrm{~mm}$. The standard deviation (SD) is used as a measure of station position repeatability and the results suggested that for high precision determination a cutoff elevation angle of $10^{\circ}$ should be used. Although at low elevation $-5^{\circ}$ and $7^{\circ}-$ the VMF1 performs better than the GMF/GPT2 and NMF, after $10^{\circ}$ the GMF/GPT2 is strongly in agreement with VMF1 and after $15^{\circ}$ the NMF shows similar results as VMF1 and GMF/GPT2.
\end{abstract}

\section{INTRODUCTION}

An absolute positioning method, which is able to obtain high accuracy for geodetic purposes, is the precise point positioning technique (PPP) (Zumberge et al., 1997). This technique is "precise" because it takes advantage of accurate a priori information, such as satellite orbits and clock errors (Maciuk et al., 2019), which are used during processing for elimination and/or mitigation of various sources of errors, thus resulting in precise and accurate position coordinates. Also, different precise models such as antenna phase center variations for both receiver and satellites, tidal and non-tidal effects, Earth rotation parameters with full statistical information which are improved steadily and many other parameters are needed to obtain reliable estimates. This precise a priori information can be downloaded from different individual Analysis Centers or the combined solution from International GNSS Service (IGS) at http://www.igs.org/. The main advantage of the PPP, is that it does not need data from other receivers to be able to determine its own position, thus significantly reducing the costs with the necessary equipment.

The PPP technique was implemented in several scientific softwares such as GIPSY/OASIS, developed by Jet Propulsion Laboratory (JPL) (Blewitt, 1989; Zumberge et al., 1997), Positioning And Navigation Data Analyst - PANDA -, developed at Wuhan University (Shi et al., 2008), Bernese GPS software version 5.0 and higher, developed at the Astronomical Institute of the University of Berne (Dach et al., 2007), RTKlib developed at Tokyo University of Marine Science and Technology from Japan (Takasu and Yasuda, 2009), G-Nut/Tefnut, developed by the Geodetic Observatory Pecny from the Czech Republic (Vaclavovic et al., 2013). Also, the PPP method was implemented in a series of online PPP services such as: GAPS developed by the University of New Brunswick, CSRS-PPP developed by Natural Resources Canada (NRCan), Automatic Precise Positioning Service (APPS) developed by Jet Propulsion Laboratory (JPL), magic GNSS developed 
by GMV and also other universities and research centers developed the possibility of using the PPP method online.

The PPP approach demonstrated over the years that it is a powerful tool that can be employed in atmospheric water vapor sensing (Dodson et al., 1996; Douša, 2009; Nistor and Buda, 2015, 2017), oceantide measurements (King and Aoki, 2003), earthquake and tsunami monitoring (Shi et al., 2010), geodynamics applications (Azúa et al., 2002; Hammond, 2005; Williams and Willis, 2006; Nistor and Buda, 2016a, 2016b; Maciuk and Szombara, 2018; Nastase et al., 2020), remote sensing (Jin and Komjathy, 2010; Maciuk, 2019), as well as 3D terrain modelling (Suba et al., 2017) and many other positioning applications.

The zenith tropospheric delay (ZTD) and precipitable water vapor (PWV) generated from GNSS measurements represents an important asset in atmospheric sciences and climate research due to the fact that they are continuously assimilated into the numeric weather prediction (NWP) models. It is essential to know that the delay caused by the troposphere does not depend on frequency, therefore it cannot be eliminated by using a linear combination of L1 and L2 observations and thus, both the pseudorange and carrier phases are identically affected. The tropospheric delay can be modeled as a zenith hydrostatic delay (ZHD) and a wet component - zenith wet delay (ZWD). The hydrostatic component is composed of dry gases, especially nitrogen and oxygen in hydrostatic equilibrium (Saastamoinen, 1973). The delay caused by this component varies with temperature and atmospheric pressure in a predictable manner and it is responsible of about $90 \%$ of the delay. Although both hydrostatic and wet component vary due to the weather conditions, the latter, which is caused by the water vapor present in the troposphere, tends to vary much faster than the hydrostatic component.

The refractive delay of the GNSS signal passing through the troposphere can be detected and used to derive information about the state of the atmosphere. The influence of the neutral atmospheric delay on the GNSS signal called zenith tropospheric delay (ZTD) can be computed based on the phase observations (Zhao et al., 2018). The main purpose of the tropospheric mapping functions is to convert the tropospheric signal delay along the zenith direction to the line of sight towards the GNSS satellite or in the case of Very Long Baseline Interferometry technique (VLBI) towards the point source, because in general, the observations are not made in the zenith direction, thus the total zenith tropospheric delay (ZTD) has to be mapped to the desired slant delay. This transformation of the ZTD to the slant tropospheric delay (STD) is done with the so-called tropospheric mapping function (MF), in which the hydrostatic and wet component are in general computed separately due to their significantly different height distribution (Boehm et al., 2006; Kouba, 2009). The most frequently used mapping functions for geodetic space technology are: Niell Mapping Function (NMF), Global Mapping Function (GMF) in conjunction with Global Pressure and Temperature (GPT) and the updated version GPT2 and/or GPT3 and Vienna Mapping Function 1 (VMF1). The main differences between these different tropospheric mapping functions are: a) in NMF the coefficients of the hydrostatic mapping functions depend on the latitude and height above the sea level of the GNSS station and the day of year, whereas the dependence of the wet mapping functions is only dependent on the GNSS site latitude (Niell, 1996) - in this case only the seasonal dependence of the temporal variation is taken into account (Boehm et al., 2006b) b) the GMF is based on climatological data - using 3 years of data - September 1999 to August 2002 adopting a $15^{0} \times 15^{0}$ global grids of monthly mean profiles for temperature, pressure and humidity provided by the European Centre for Medium-Range Weather Forecast (ECMWF) (Boehm et al., 2006b); the GPT2 is able to eliminate the weakness given by the limited spatial and temporal variability of the GPT/GMF, which is providing the pressure, lapse rate, temperature, water vapor pressure and mapping function coefficient at any site, resting upon $5^{0}$ grid of mean values, semi-annual and annual variation in all parameters (Lagler et al., 2013); the data used are monthly mean profiles of the latest European Centre for Medium-Range Weather Forecasts (ECMWF) and incorporates semi-annual harmonics to better account for regions where very rainy or very dry periods dominate (Lagler et al., 2013); c) the VMF1 introduced by (Boehm et al., 2006a) uses the data from Numerical Weather Models (NWM) to provide information related to the location of the site with temporal resolution of six hours; in VMF1 the "c" coefficient from ray tracing is fitted to a function of latitude and day of the year to remove the systematic errors.

It was demonstrated by different authors like (Bevis et al., 1992; Niell, 1996; Boehm et al., 2006b; Kouba, 2009; Lagler et al., 2013; Wang et al., 2013; Kačmařík et al., 2017) that due to the high variability of the non-hydrostatic part of the atmosphere especially for low elevation angle observation, mapping functions represent a major challenge in GNSS data processing.

Boehm et al. (2006b) showed that not only the tropospheric delay estimates are changing by using different MF, but they also have an influence on the vertical position estimates. It was concluded that the VMF1 and GMF are in good agreement, whereas NMF presented large differences, with station height differences up to $10 \mathrm{~mm}$, not only on the southern hemisphere, but also in the northern hemisphere in China and Japan. The problem of these changes in height, is that they will be translated into changes of baseline length and repeatability. By using information that is not accurate enough regarding the surface pressure, this leads to errors in the a priori ZHD values, which results in corrupt estimates of the 
ZTD and station heights (Tregoning and Herring, 2006).

The main purpose of this study is to evaluate the influence of different mapping functions, at different cutoff elevation angles of: $5^{0}, 7^{0}, 10^{\circ}$ and $15^{\circ}$. Four stations from EUREF network situated in different environments: one station is near the sea; one station is near the mountains; and two of them are situated into mountainous area. In this study is assessed the influence of the MF and elevation cutoff angle on LC, PC postfit residuals, daily variability and their repeatability. The resulting position estimates have been computed into the IGb08 reference frame.

\section{MATERIALS AND METHODS}

The explicit relationship between the observations and unknowns is given by the functional model. To connect the GNSS measurements to the unknowns we can use the Least Square Method. To be able to mitigate the first order ionospheric effect, we can use the traditional ionosphere free pseudorange (PC) and ionospheric free phase carrier (LC) linear combination (Zumberge et al., 1997; Héroux and Kouba, 2001):

$P C=\rho+C(d t-d T)+T_{r}+\varepsilon_{P}$

$L C=\rho+C(d t-d T)+T_{r}+N \lambda+\varepsilon_{\Phi}$

where: $P C$ is the ionosphere-free combination of $\mathrm{L} 1$ and L2 pseudoranges (2.55P1-1.55P2), LC is the ionospheric free combination of L1 and L2 carrier phase $\left(2.55 \Phi_{1}-1.55 \Phi_{2}\right), d t$ is the station clock offset from GPS time, $d T$ is the satellite clock offset from GPS time, $C$ is the vacuum speed of light, $T_{r}$ is the signal path delay due to the neutral atmosphere, $\lambda$ is the carrier, or carrier combination, $N$ is the ambiguity of the carrier-phase ionospheric free combination and $\varepsilon_{P}, \varepsilon_{\Phi}$ are the relevant measurement noise component, including multipath; $\rho$ is the geometrical range computed as a function of satellite $\left(\mathrm{X}_{\mathrm{S}}, \mathrm{Y}_{\mathrm{S}}, \mathrm{Z}_{\mathrm{S}}\right)$ and station $(x, y, z)$ coordinates according to:

$\rho=\sqrt{\left(X_{S}-x\right)^{2}+\left(Y_{S}-y\right)^{2}+\left(Z_{S}-z\right)^{2}}$

Expressing the tropospheric path delay $T_{r}$ as a function of zenith tropospheric delay (ZTD) and mapping function (MF $-m f$ ) and removing the know satellite clock $(d T)$ - obtained from the precise products - for example from IGS, gives the following PPP mathematical model in the simplest form:

$f(P)=\rho+C d t+m f_{Z P D}+\varepsilon_{P}-P C=0$

$f(\Phi)=\rho+C d t+m f_{Z P D}+N \lambda+\varepsilon_{\Phi}-L C=0$

\subsection{NIELL MAPPING FUNCTION (NMF)}

Niell (1996) developed his mapping function (NMF) using the coordinates of the stations and temporal changes rather than surface meteorological parameters.

The observation made from the satellite to the receiver is related to the zenith delay by using a mapping function, which is able to model with sufficient accuracy for elevations down to $3^{0}$ using a continued fraction in sin (elevation) (Niell, 1996), given by:

$$
\begin{aligned}
& f_{i}(e)=\frac{1+\frac{a_{i}}{1+\frac{b_{i}}{1+c_{i}}}}{\sin e+\frac{a_{i}}{\sin e+\frac{b_{i}}{\sin e+c_{i}}}}+ \\
& +[\underbrace{\frac{1}{\sin e}-\left(\frac{1+\frac{a_{h t}}{1+\frac{b_{h t}}{1+c_{h t}}}}{\sin e+\frac{a_{h t}}{\sin e+\frac{b_{h t}}{\sin e+c_{h t}}}}\right)}_{\text {height correction terms }}]
\end{aligned}
$$

Where: e is the elevation:

- $\quad \mathrm{i}=\mathrm{h}, \mathrm{w}$; designated indices of " $\mathrm{h}$ " - hydrostatic; w - wet;

- $\quad$ a, b, c, are different parameters for the hydrostatic and wet components of the atmosphere and they are a constant or a function of the site latitude symmetric about the equator, and day of year. They should be correlated with sufficient accuracy to the accuracy of the troposphere at the moment of the time of the observation to avoid introducing large errors into the estimation of the station position. In this case only the seasonal dependence of the temporal variation of the troposphere is taken into account.

\subsection{GLOBAL MAPPING FUNCTION (GMF)/GLOBAL PRESSURE AND TEMPERATURE 2 (GPT2)}

By taking monthly mean profiles for temperature, pressures and humidity from the ECMWF using global grids at $15^{0} \times 15^{0}, 40$ years reanalysis data (ERA40), the coefficients $a_{h}$ and $a_{w}$ were estimated for the period September 1999 to August 2002, in which they used the same strategy that was used for VMF1 (Boehm et al., 2006b). The hydrostatic and wet parameters $a$ were obtained from the empirical equation $b$ and $c$ (from VMF1) in which the parameters $a$ were derived by a single raytrace at $3.3^{0}$ initial elevation angle, at each 312 grid points and 36 monthly mean values (Boehm et al., 2006b). By applying the height correction terms from eq. (6) given by (Niell, 1996), the hydrostatic coefficients were reduced to mean sea level.

The annual amplitudes, $A$, and the mean values $a_{0}$ of the sinusoidal function given by eq. (7), were fitted to the time series of the $a$ parameters at each grid point, with the phase referred to January 28, corresponding to the NMF:

$$
\begin{aligned}
& a=a_{0}+A \cos \left(\frac{\text { doy-28 }}{365} 2 \pi\right) \\
& \begin{array}{c}
a_{0}=\sum_{n=0}^{9} \sum_{m=0}^{n} P_{n m}(\sin \varphi) *\left[A_{n m} \cos (m * \lambda)+\right. \\
\left.\quad+B_{n m} \sin (m * \lambda)\right]
\end{array}
\end{aligned}
$$

where: $P_{n m}-$ is the Legendre polynomials; $\varphi$ and $\lambda$ are the latitude and longitude, $A_{n m}$ and $B_{n m}$ are the coefficients for degree $n$ and $m$ which are determined within a least-square adjustment. 
At each single grid point with respect to eq. (7) the standard deviation of the monthly values increase toward higher latitude, with a max value of $8 \mathrm{~mm}$ (equivalent station height error) in Siberia (Boehm et al., 2006b). Regarding the wet component, the appropriate standard deviation is smaller with $3 \mathrm{~mm}$ maximum values at the equator. According to eq. (8), the global grid mean values $a_{0}$ and of the amplitudes $A$, for the wet and hydrostatic coefficients, were expanded into spherical harmonic coefficients up to degree and order 9 in a least-square adjustment.

The GPT2 is an empirical model with a refined resolution of $5^{0}$ that uses 10 years of data (2001-2010) from the global monthly mean profiles for temperature $(\mathrm{T})$, pressure (p), specific humidity (Q) and geopotential from ERA-Interim (Dee et al., 2011) discretized at 37 pressure level and $1^{0}$ of latitude and longitude. In the GPT2 not only the mean and annual variations are taken into account, but also it incorporates semi-annual harmonics to better account for regions where very rainy periods or very dry periods dominate (Lagler et al., 2013). Also, the GPT2 uses mean values and (semi-)annual variations of the temperature and lapse rate at every individual grid point.

\subsection{VIENNA MAPPING FUNCTION (VMF1)}

The Vienna Mapping Function introduced by Boehm and Shuh (2004) adopts a more rigorous approach in utilizing the NWM for the MF determination and namely, the first and most significant MF coefficients $a_{h}$ and $a_{w}$ from eq. (6), are fitted four times a day at each station to ray-tracing with the NWM of the ECMWF, while retaining functional representation for the remaining hydrostatic and wet coefficients $b_{h}, b_{w}, c_{h}$ and $c_{w}$, thus resulting in the MF called Vienna Mapping Function (VMF) (Kouba, 2008).

An updated version of the VMF, in which the empirical representation of the coefficients $b_{h}, b_{w}, c_{h}$ and $c_{w}$ are improved, thus resulting in a better fit for the first coefficients $a_{h}$ and $a_{w}$ from eq. (6), results in the so called VMF1.

The original VMF1 parameters are site dependent and they are available for specific sites, although the Vienna University of Technology is making available the VMF1 for all VLBI stations starting from 1979 and for most IGS stations from 2004, thus this site-dependency, represents a major limitation of the VMF1. So, it cannot be used for GNSS processing prior to 2004, for stations not included in the VMF1 IGS or VLBI site list (Kouba, 2008). To be able to overpass this shortcoming, VMF1 data were generated on a global $2.0^{0} \times 2.5^{0}$ grid starting from 1994 which was made available in June 2006 (J. Boehm, personal communication, 2006) based on the ECMWF NWM. The VMF1 grids include hydrostatic and wet mapping functions coefficients as well as the hydrostatic and wet zenith tropospheric delay (ZTD) which makes VMF1 available at any site, any time after 1994. They are given for four daily epochs: $0,6,12,18 \mathrm{~h} \mathrm{UT}$ and consist of four global $2.0^{\circ}$ x $2.5^{0}$ grid files of $a_{h}, a_{w}, z_{h}$ and $z_{w}$ in which the last two terms represents the hydrostatic zenith delay and wet zenith delay.

\subsection{SLANT TROPOSPHERIC DELAY (STD) AND TROPOSPHERIC GRADIENTS}

The slant tropospheric delay (STD) is given by the following equation:

$$
\begin{array}{rl}
S T D(\text { ele }, a z i) & =Z H D * m f_{h}(\text { ele })+ \\
+Z W D & * m f_{w}(\text { ele })+G R(\text { ele }, a z)+\varepsilon
\end{array}
$$

where: $Z H D$ - is the zenith hydrostatic delay; $m f_{h}$ is the mapping function for the dry delay; $Z W D$ - is the zenith wet delay; $m f_{w}$ - is the mapping function for the wet delay; $G R$ - is the horizontal gradient delay as a function of elevation (ele) and azimuth (az); $\varepsilon-$ is the post-fit residual.

The zenith tropospheric delay (ZTD) is providing information above the GNSS receiver in the direction of the zenith, whereas the tropospheric gradients offer us information about the first-order spatial asymmetry around the receiver. In our case, the tropospheric gradients are solved as a Random Walk wet delay (RWWD), which is given by:

$$
\begin{aligned}
R W W D & =m f(e)\left(Z T D+\cot (e) *\left(G_{n} \cos (\varphi)+\right.\right. \\
& \left.+G_{e} * \sin (\varphi)\right)
\end{aligned}
$$

where: $m f(e)$ is the elevation mapping function; $e$ is the elevation, $Z T D$ is the zenith tropospheric delay; $G_{n}$ and $G_{e}$ are the gradient parameters.

\section{DATA AND PROCESSING STRATEGY}

The analysis was done on 4 GNSS EUREF stations for a period of one month, October 2015. All 4 stations used a Leica LEIAT504 antenna type and LEICA GRX1200PRO receiver, except COST which had a LEICA GRX1200+GNSS receiver. In this month at all four stations the temperature had a mean value of $15^{\circ} \mathrm{C}$ and there were 3 to 6 days with precipitations, having a maximum of $15 \mathrm{~mm}$ per day.

The processing was made with the help of the Jet Propulsion Laboratory's software GIPSY/OASIS II (Zumberge et al., 1997).

The data is analyzed based on: I) LC and PC postfit residuals; II) daily variability of the North, East and Up component; III) evaluation of coordinates repeatability.

The analyzed data was processed in four stages using different MF: a) using the GMF/GPT2; b) Niell mapping function; c) VMF1 and d) no mapping function. In the no mapping case, the hydrostatic component of the ZTD is estimated using Saastamoinen model (Saastamoinen, 1973) and the wet component is neglected. The computations were done at four different elevations: $5^{0} ; 7^{0} ; 10^{0} ; 15^{0}$. 


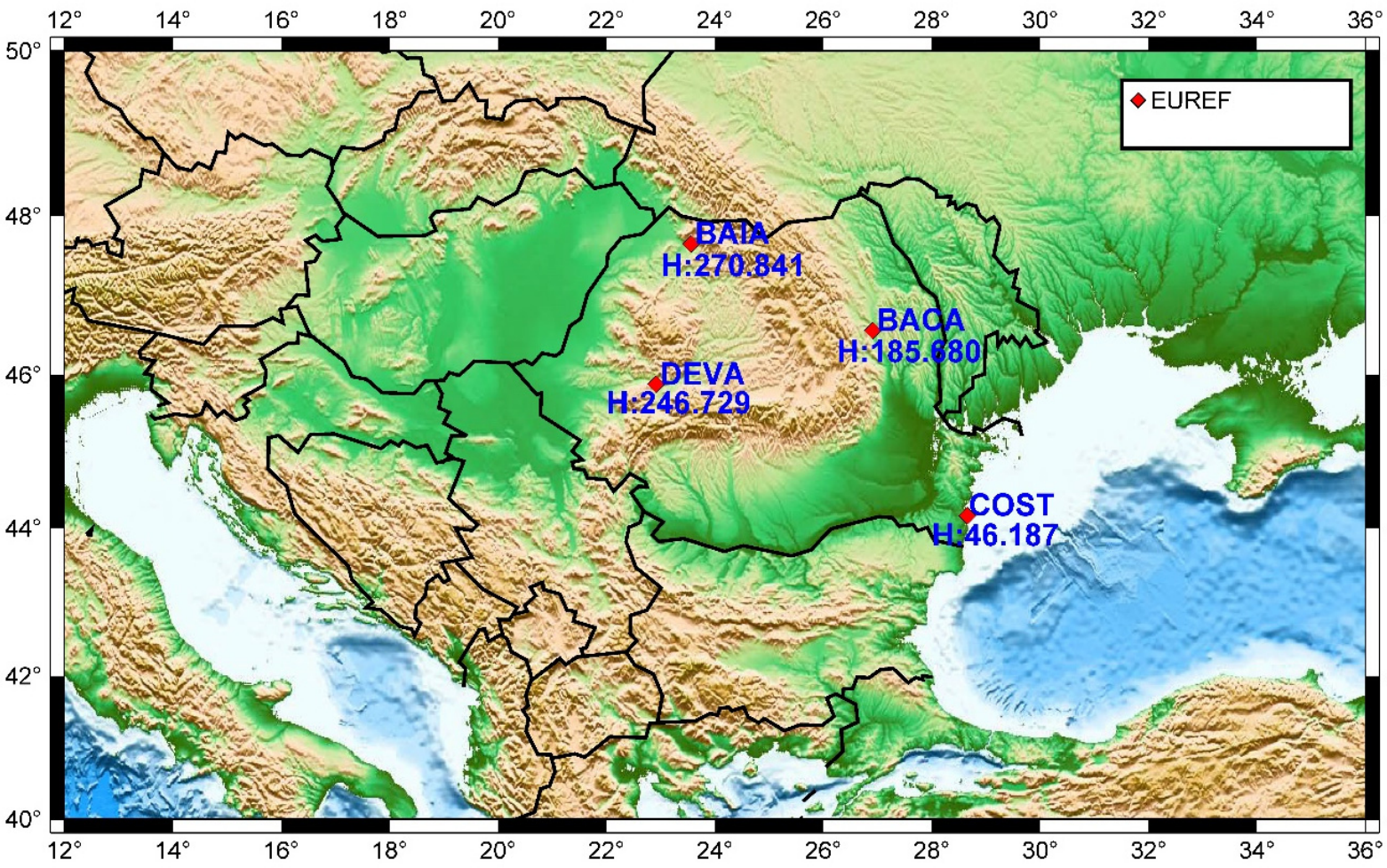

Fig. 1 Stations location and the height of the GNSS receivers.

The processed stations are presented in Figure 1 with their heights.

The settings used during Precise Point Positioning processing are presented in Table 1.

\section{RESULTS}

\subsection{LC AND PC POSTFIT RESIDUALS EVALUATION}

In the first stage, we have done the analysis on the LC and PC postfit residuals. The operation was done at different cutoff elevation angles: $5^{0} ; 7^{0} ; 10^{0}$; $15^{0}$. The values are presented in Table 2.

From Table 2 we can notice that the LC and PC postfit residuals on all four cases are higher at the $5^{0}$ elevation cutoff angle and it is decreasing slowly until the $15^{0}$ elevation cutoff angle. For the VMF1 there is a decrease of the LC postfit residual at the change of elevation cutoff angle from $5^{0}$ to $10^{0}$ for the stations COST and BACA of approximately the same: $\sim 7 \%$ and $\sim 10 \%$. When we change the elevation cutoff angle from $10^{0}$ to $15^{0}$, the decrease of the postfit residuals is $\sim 12 \%$ for BACA and for COST station is $\sim 15 \%$. From Figure 1 it can be observed that the station COST is very close to the sea and has the lowest height and the station BACA is the next from the remaining three stations with the lower height. Between these two stations there isn't any high obstacle such as high mountains, compared to the stations BAIA and DEVA which are located in a mountainous area. The stations BAIA and DEVA have a similar pattern on decreasing the LC postfit residuals on all four stages when the elevation increases, of $\sim 3$ $\%, \sim 5 \%$ and $\sim 11 \%$. It seems that the decrease of the
LC postfit residuals in the case of BAIA and DEVA is slower than compared to the stations BACA and COST on all elevation cutoff angles. The same pattern can be observed when the GMF/GPT2 is used, with a difference compared to the VMF1, of maximum of 0.3 $\%$. This maximum difference can be observed when we change the elevation cutoff angle from $5^{0}$ to $10^{\circ}$, but when changing the elevation from $10^{0}$ to $15^{0}$ the difference is at the level of $0.1 \%$. In the case of the $\mathrm{NMF}$, there is a decrease of the LC postfit residual when we change the elevation cutoff angle from $5^{0}$ to $15^{0}$ for the stations COST and BACA of approximately the same: $\sim 7 \%, \sim 14 \%$ and $\sim 19 \%$. For stations BAIA and DEVA there isn't the same pattern of decreasing the LC postfit residuals as in the case of GMF/GPT2 and VMF1. In the case of NMF, all stations between the elevation cutoff angle from $7^{0}$ to $10^{\circ}$, in terms of LC postfit residuals, are decreasing with a $7 \%$ with each value interval. In the case of VMF1 and GMF/GPT2, the decrease is only at the level of $4 \%$. In the case of no mapping, all the stations have a similar pattern of decreasing the LC postfit residuals with the increase of the elevation. The LC postfit residuals change approximatively with $6 \%$ when the elevation cutoff angle is changed from $10^{\circ}$ to $15^{0}$ on all stations. We have to understand that not only the tropospheric delays can generate these changes the tropospheric delay represents only a part from the total of the postfit residuals - there can be specific objects that can obstruct the GNSS signal that leads to the multipath effect. For the PC postfit residuals all three $\mathrm{MF}$ and the no mapping case, produce similar 
Table 1 Summary of GNSS PPP processing strategies.

\begin{tabular}{|c|c|}
\hline Items & Description \\
\hline Number of stations & 4 \\
\hline Satellite constellation & GPS \\
\hline Estimator & $\begin{array}{l}\text { Stochastic Kalman filter/smoother implemented as square root information } \\
\text { filter with smoother }\end{array}$ \\
\hline Basic Observable & $\begin{array}{l}\text { Undifferenced ionosphere-free carrier phase, LC } \\
\text { Undifferenced ionosphere-free pseudorange, PC }\end{array}$ \\
\hline Elevation angle cutoff: & $5^{0} ; 7^{0} ; 10^{0} ; 15^{0}$ \\
\hline Sampling rate: & $30 \mathrm{~s}$ \\
\hline Data weight, LC: & $0.01 \mathrm{~m}$ \\
\hline Data weight, PC: & $1.0 \mathrm{~m}$ \\
\hline Elevation weighting: & sqrt $(\sin ($ elevation $)) /$ sigma \\
\hline Modeled observable & $\begin{array}{l}\text { Undifferenced LC and PC combinations, } \\
\text { CA-P1 biases from CODE applied }\end{array}$ \\
\hline Troposphere & $\begin{array}{l}\text { Tropospheric delay: } \\
\text { ZHD: corrected with global pressure and temperature GPT2 model using the } \\
\text { formulas of Saastamoinen } \\
\text { ZWD: estimated every } 30 \text { seconds as a time dependent parameter together } \\
\text { with } 2 \text { tropospheric gradients, by using a Kalman filter approach. } \\
\text { Mapping Function: } \\
\text { 1) GMF/GPT2 } \\
\text { 2) Niell } \\
\text { 3) VMF1 } \\
\text { 4) No mapping functions }\end{array}$ \\
\hline Tropospheric gradients & $\begin{array}{c}\text { The gradient parameters were modeled as random walk variables as } \\
\text { presented in equation (10) using each MF individually }\end{array}$ \\
\hline Ionosphere & 1st order effect: Removed by LC and PC combinations \\
\hline Tidal & $\begin{array}{l}\text { Solid Earth tide, pole tide, ocean tide loading corrections according } \\
\text { to IERS Conventions } 2010\end{array}$ \\
\hline Orbit Models & Final precise orbits and clock products from JPL, with arc length of 30 hours \\
\hline Phase wind-up effect & Corrected \\
\hline Ambiguity & $\begin{array}{c}\text { The ambiguities were resolved by using wide lane phase biases (WLPB) } \\
\text { products from JPL, in } 2 \text { iterations }\end{array}$ \\
\hline Phase center offset (satellite) & Corrected using IGS values for all GPS satellites \\
\hline Receiver antenna PCOs and PCVs & PCO and PCV corrections for GPS are from igs08.atx \\
\hline Station coordinates & Estimated as static \\
\hline
\end{tabular}

Table 2 LC and PC mean residual using different MF at different cutoff elevation angles.

\begin{tabular}{crcccccccc}
\hline & \multicolumn{1}{c}{ LC } & \multicolumn{4}{c}{ PC } \\
\hline Sta. & ELEV & $\begin{array}{c}\text { VMF1 } \\
(\mathrm{mm})\end{array}$ & $\begin{array}{c}\text { GMF/GPT2 } \\
(\mathrm{mm})\end{array}$ & $\begin{array}{c}\text { NIELL } \\
(\mathrm{mm})\end{array}$ & $\begin{array}{c}\text { NO_MAPP } \\
(\mathrm{mm})\end{array}$ & $\begin{array}{c}\text { VMF1 } \\
(\mathrm{cm})\end{array}$ & $\begin{array}{c}\text { GMF/GPT2 } \\
(\mathrm{cm})\end{array}$ & $\begin{array}{c}\text { NIELL } \\
(\mathrm{cm})\end{array}$ & $\begin{array}{c}\text { NO_MAPP } \\
(\mathrm{cm})\end{array}$ \\
\hline & $\mathbf{5}$ & 6.64 & 6.65 & 8.50 & 14.25 & 60.73 & 62.09 & 60.80 & 60.59 \\
BACA & $\mathbf{7}$ & 6.18 & 6.21 & 7.85 & 14.08 & 58.82 & 60.73 & 58.84 & 58.60 \\
& $\mathbf{1 0}$ & 5.56 & 5.57 & 6.75 & 13.67 & 56.51 & 55.73 & 56.49 & 56.27 \\
& $\mathbf{1 5}$ & 4.87 & 4.88 & 5.53 & 12.95 & 52.00 & 51.99 & 51.97 & 51.87 \\
\hline & $\mathbf{5}$ & 9.45 & 9.50 & 10.82 & 15.20 & 73.05 & 73.05 & 72.89 & 72.89 \\
BAIA & $\mathbf{7}$ & 9.25 & 9.29 & 10.55 & 15.09 & 72.25 & 72.25 & 72.11 & 72.12 \\
& $\mathbf{1 0}$ & 8.80 & 8.82 & 9.73 & 14.68 & 70.05 & 70.05 & 69.97 & 70.00 \\
& $\mathbf{1 5}$ & 7.81 & 7.82 & 8.74 & 13.03 & 66.74 & 66.74 & 66.67 & 66.66 \\
\hline & $\mathbf{5}$ & 7.78 & 7.81 & 9.46 & 13.34 & 80.77 & 80.77 & 80.82 & 80.79 \\
COST & $\mathbf{7}$ & 7.26 & 7.27 & 8.83 & 13.00 & 78.00 & 78.00 & 78.00 & 78.00 \\
& $\mathbf{1 0}$ & 6.54 & 6.54 & 7.65 & 12.51 & 73.36 & 73.36 & 73.35 & 73.35 \\
& $\mathbf{1 5}$ & 5.56 & 5.56 & 6.16 & 11.25 & 65.97 & 65.97 & 65.99 & 66.03 \\
\hline & $\mathbf{5}$ & 7.92 & 7.98 & 9.33 & 14.69 & 95.70 & 95.70 & 95.73 & 95.95 \\
DEVA & $\mathbf{7}$ & 7.66 & 7.68 & 8.95 & 14.55 & 93.05 & 93.05 & 93.06 & 93.27 \\
& $\mathbf{1 0}$ & 7.25 & 7.26 & 7.96 & 14.16 & 90.54 & 90.54 & 90.55 & 90.64 \\
\hline
\end{tabular}


results, in which the decrease for the COST and BACA stations appears to have similar behavior. A similar pattern can be noticed on BAIA with DEVA, as in the case of LC postfit residuals.

In Figure 2 the scatter of the mean value is presented for the LC postfit residuals for the station BACA using the three MF and no mapping function. The mean value was computed by taking each individual solution over a 24 -hour period and stacking all the 31 days. The residuals exceeding \pm 3 times the standard deviation were excluded from the computation of the mean. The mean value was then plotted to observe the behavior during a 24-hour period. The station BACA was chosen because it had the lowest values of the LC postfit residuals when using all three MF.

The increase of the postfit residuals on lower elevation is due to the fact that the observation taken at $5^{0}, 7^{0}$ have higher noise. On all cases when MF was used - A1) to H) by increasing the elevation cutoff angle there is a significant decrease for the LC postfit scatter. It can be seen that the best result for LC postfit residuals are when the VMF1 mapping function was used. In all the cases, the LC postfit residuals is the highest, when no mapping function was used. It can be seen that on all 4 elevation angles, the VMF1 and GMF/GPT2 are in agreement at the level of 0.01 0.03 $\mathrm{mm}$. The largest differences between MF are at lower elevation angles and start decreasing as the elevation raises.

Between the VMF1 and NMF, the LC postfit residuals differ at a level of $1 \sim 2 \mathrm{~mm}$. It seems that at lower elevation angle $-5^{0}$ and $7^{0}-$ the A2) and B2) the NMF is more sensitive to the presence of the wet component in the troposphere, than the VMF1. At $10^{\circ}$ cutoff elevation angles, the difference between NMF and VMF1, becomes much lower and at the $15^{\circ}$ elevation angle, the two MF, are almost in perfect agreement.

From Figures $2-$ E) to $H$ ) we can observe no mapping results that for all the elevation cutoff angles, there is a strong wet component which is absorbed into LC postfit residuals whereas the VMF1 is able to perform very well in the presence of this component. In the case of no mapping function with the increase of the elevation cutoff angle, there isn't a noticeable decreasing of the scatter of the LC postfit residuals.

By analyzing the A2), B2) and C2) it appears that the NMF is not able to account correctly rapid variation of the zenith wet delays at lower elevation and NMF comes is agreement with VMF1 and GMF/GPT2 only at $15^{0}$ cutoff elevation angles. The results in which the VMF1, NMF and GMF/GPT2 have different results are at lower elevation $-5^{0}$ to $10^{\circ}$, but they start to be in agreement from an elevation angle of $15^{\circ}$ is also confirmed by (Qiu et al., 2020).

The mean LC postfit residuals as a function of elevation with a cutoff angle of $5^{0}$ is presented in Figure 3 . The mean value was computed by taking each individual solution over a 24-hour period with approximately the same elevation and stacking all the 31 days. The residuals exceeding \pm 3 times the standard deviation, were excluded from the computation of the mean. The mean value of the LC residuals was then plotted as a function of elevation angles.

In Figure 3 the stations BACA and BAIA which present the lowest respectively the highest values of the LC mean residual using different MF are plotted. We compared the results for the LC postfit residuals in a) using GMF/GPT2 and VMF1; b) using NMF and VMF1; and on c) no mapping and VMF1 at $5^{0}$ cutoff elevation angles. As we can see, the scatter is much larger for low elevation. For the station BACA between the VMF1 and GMF/GPT2 there is only a small difference in the scatter that can be seen at $5^{0}$ to $7^{0}$ which tends to disappear with the increase of the elevation. As for the NMF and VMF1, we see that the difference in scatter is present until an elevation cutoff angle up to a $40^{\circ} \sim 50^{\circ}$, then both MF tend to present similar results. From this difference we can see that the NMF is not able to estimate the entire amount of wet delay contained into the troposphere.

In case of station BAIA, we can observe that there is a large scatter of the LC postfit residuals, which in turn generates higher LC postfit residuals. Although the low elevation observations are more susceptible to: changes in troposphere, a lower signal to noise ratio and multipath effects, which generate higher level of noise and systematic errors in the observations. From the postfit residuals distribution we can see that the large scatter of the LC postfit residuals are seen also on mid elevation angles.

In the case of station BAIA, all three MF presents similar results, especially above $15^{\circ}$ elevation angles.

The results presented in Figure 4 show how slant tropospheric delay (STD) is behaving using VMF1 and no mapping as a function of elevation angle. The slant tropospheric delay (STD) was computed using eq. (9). The mean value was computed by taking each individual solution over a 24-hour period with approximately the same elevation and stacking all the 31 days. The residuals exceeding \pm 3 times the standard deviation were excluded from the computation of the mean. The slant tropospheric delay presented in Figure 4, is between the VMF1 and when no mapping was used, for all four stations. It can be observed that the delay caused by the troposphere, is nearly $25 \mathrm{~m}$ at $5^{0}$ and around $4 \mathrm{~m}$ at $40^{\circ}$. The results are in agreement with the findings done by (Williams and Nievinski, 2017). At all four stations with the increase of the elevation angle the two MF start to spread apart, at $5^{0}$ they are at a difference of $0.5 \sim 0.7 \mathrm{~m}$ and at $30^{\circ}$ they are at a difference of 2 2.5 m. At the station COST, which is near to the sea, the VMF1 and no mapping has values that are closer at $5^{0}$ elevation and then there is a rapid spread with the increase of the elevation, having the largest difference between the values starting from $10^{\circ}$ elevation from all the four stations. 


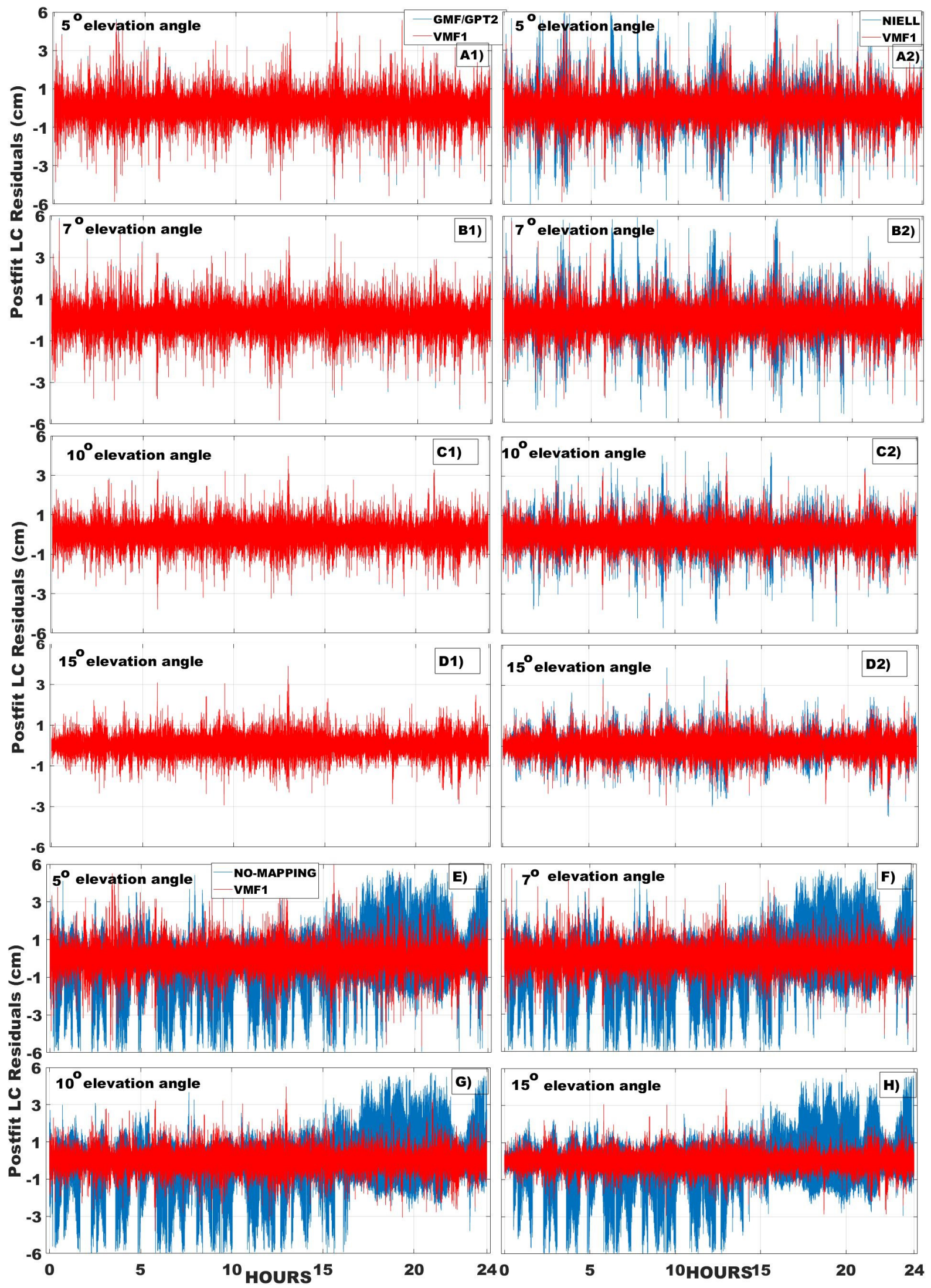

Fig. 2 Results for station BACA: In A1), B1), C1) and D1) is the LC postfit residuals from using VMF1 and GMF/GPT2; in A2), B2), C2) and D2) is the LC postfit residuals from using VMF1 and NMF; in E), F), $\mathrm{G})$ and $\mathrm{H}$ ) is the LC postfit residuals from using VMF1 and no mapping function. The elevation angle was at $\left.\left.\left.\left.\left.\left.\left.\left.\left.\left.\left.5^{0}-\mathrm{A} 1\right)-\mathrm{A} 2\right)-\mathrm{E}\right) ; 7^{0}-\mathrm{B} 1\right)-\mathrm{B} 2\right)-\mathrm{F}\right) ; 10^{0}-\mathrm{C} 1\right)-\mathrm{C} 2\right)-\mathrm{G}\right) ; 15^{0}-\mathrm{D} 1\right)-\mathrm{D} 2\right)-\mathrm{H}$ ). 


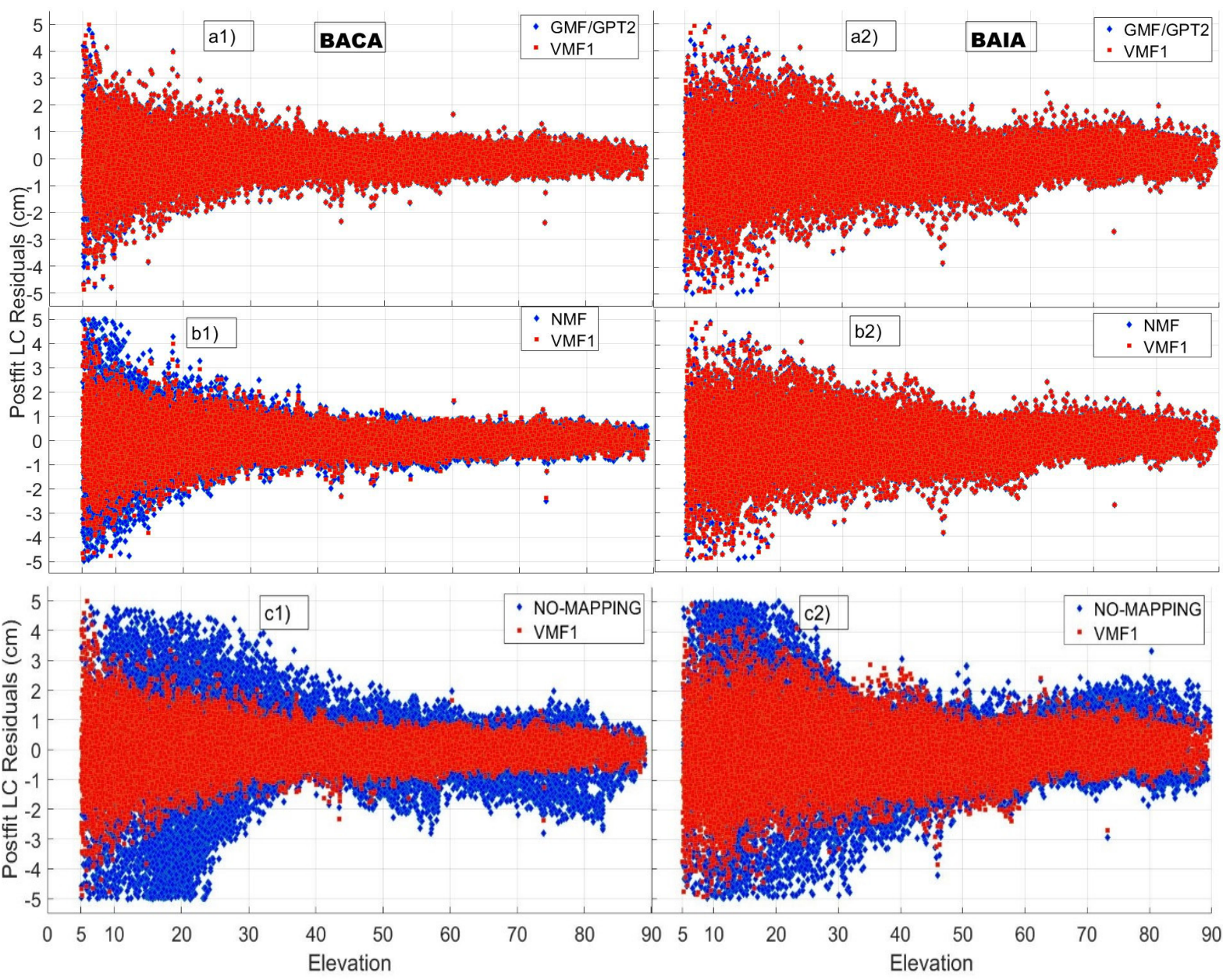

Fig. 3 LC postfit residuals at $5^{0}$ cutoff elevation angle for stations: BACA and BAIA; In the plots numbered with a) we have the results by using GMF/GPT2 and VMF1; in the b) the results by using NMF and VMF1; and on c) no mapping and VMF1.
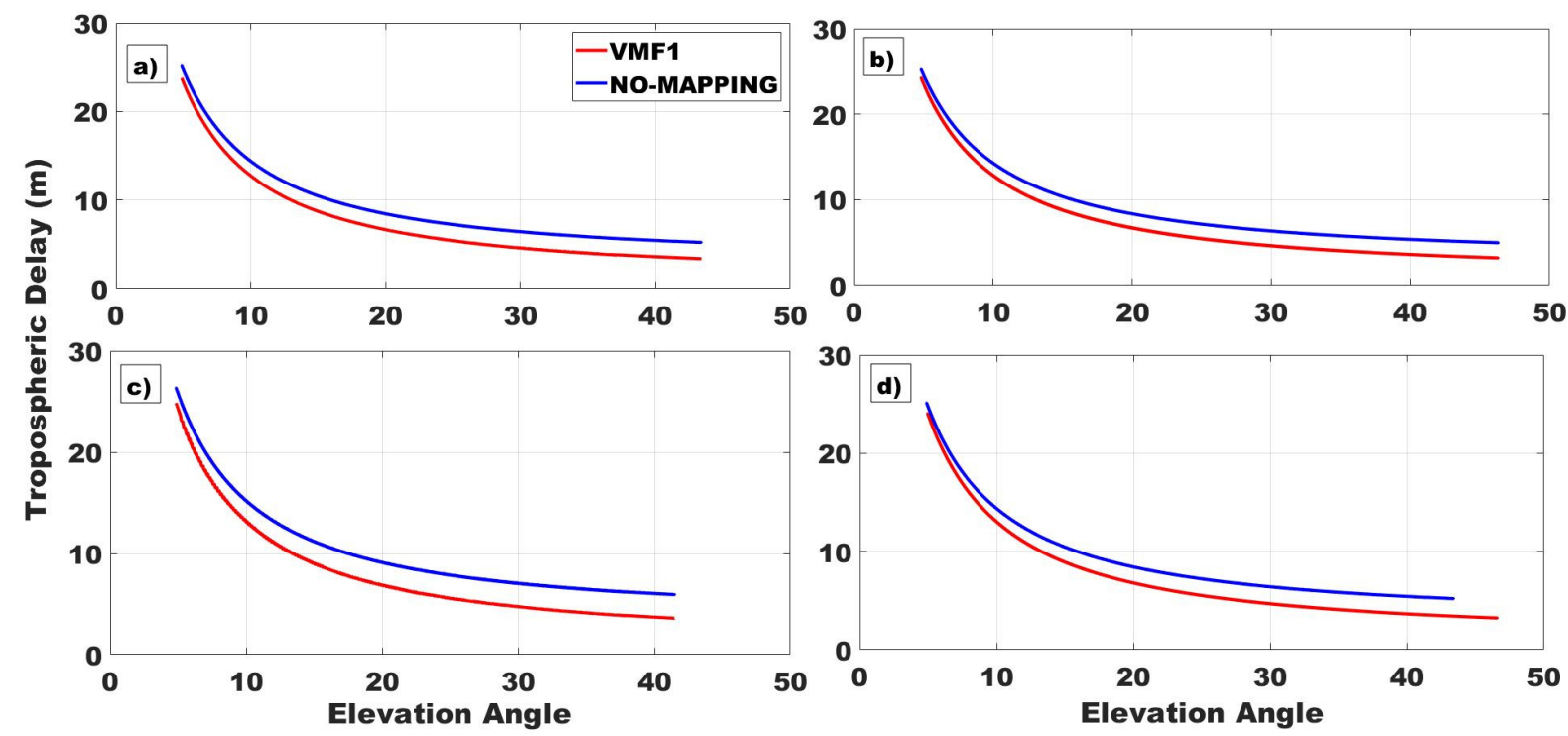

Fig. 4 Direct slant tropospheric delay (hydrostatic + wet) as a function of the satellite elevation angle for site: a) BACA, b) BAIA, c) COST and d) DEVA. 


\subsection{DAILY VARIABILITY FOR THE NORTH, EAST AND UP COMPONENT USING DIFFERENT ELEVATION CUTOFF ANGLE AND DIFFERENT MF}

The coordinates variability on all three components - North, East and Up, was assessed when different mapping functions and elevation cutoff angles was used during processing. The results at $5^{0}$ elevation cutoff angle and using different MF for the North and East component is presented in Figure 5.

In Figure 5 the daily variability for the North and East component is presented using: GMF/GPT2, $\mathrm{NMF}, \mathrm{VMF} 1$ and no mapping function at $5^{0}$ elevation cutoff angle. To better emphasize the daily variability for each solution, due to the fact that in a few days there were extreme values, each station was framed in boxes of different size and colors: a) station BACA the green frame; b) station BAIA - the light magenta frame; c) station COST - the orange frame and d) station DEVA - the blue frame. A behavior with an extreme value can be seen on station BAIA on day 16 for the North component.

The difference between each individual daily solution by using GMF/GPT2, NMF and VMF1 is:

(a) On North component, at the level of $\sim 0.3 \div$ $0.5 \mathrm{~mm}$ with extreme values at the level of $\sim 1.0 \mathrm{~mm}$ for 5 to 6 days, which can be seen on all stations. The stations that experienced the largest difference, between the results from the three different MF, were, station BAIA with $\sim 4.5 \mathrm{~mm}$ on days 16,20 and 28 and for station DEVA a value of $\sim 4.0 \mathrm{~mm}$ on day 11 and 18 ,

(b) On East component the differences are at the level of $\sim 0.2 \div 0.4 \mathrm{~mm}$ with extreme values at the level of $\sim 1.0 \mathrm{~mm}$ for 2 to 4 days. The largest differences can be seen at stations BAIA with a value of $\sim 1.1 \mathrm{~mm}$ on day 5,11 and 28 and on station DEVA with a value of $\sim 1.2$ on day 5,11 , 15 and 16.

When using the no mapping strategy and comparing the results with the other three MF, the difference between each individual daily solution is:

(a) on North component for all the stations was at the level of $\sim 2.0 \div 4.0 \mathrm{~mm}$. The largest differences between daily solutions were at the level of $\sim 6.0 \div 12.0 \mathrm{~mm}$ for a period of 7 to 9 days,

(b) on East component we can summarize that the differences between the daily solutions is at the level of $\sim 2.0 \div 2.5 \mathrm{~mm}$, except for station COST where the differences are at the level of $\sim 4.5 \mathrm{~mm}$. The largest differences between daily solutions were at the level of $\sim 5.0 \div 15.0 \mathrm{~mm}$ for a period of 5 to 7 days.

The results at $5^{0}$ elevation cutoff angle and using different MF for the Up component is presented in Figure 6.

In Figure 6 the daily variability for Up component is presented using: GMF/GPT2, NMF, VMF1 and no mapping function at $5^{0}$ elevation cutoff angle - the upper part of Figure and on the lower part of Figure are only the results of the GMF/GPT2, NMF and VMF1. To better emphasize the daily variability for each solution, due to the fact that in a few days there were extreme values, each station was framed in boxes of different size and colors: a) station BACA the green frame; b) station BAIA - the light magenta frame; c) station COST - the orange frame and d) station DEVA - the blue frame. A behavior with extreme value can be seen on station DEVA on day 19.

The difference between each individual daily solution by using GMF/GPT2, NMF and VMF1 is on the Up component, at the level of $\sim 1.0 \div 1.5 \mathrm{~mm}$ with extreme values at the level of $\sim 2.2 \mathrm{~mm}$ for 6 to 10 days, which can be seen on all stations. By also using, the strategy - no mapping - the differences between each individual solution for stations BACA and BAIA, are at the level of $\sim 30.0 \div 34.0 \mathrm{~mm}$, whereas COST and DEVA are at the level of $\sim 48.5 \mathrm{~mm}$, respectively $\sim 43.0 \mathrm{~mm}$. The extreme values as a difference between each individual solution is for stations BACA and BAIA at the level of $\sim 50.0 \div 90 \mathrm{~mm}$ for a period of 4 to 5 days, respectively 6 to 8 days, whereas for stations COST and DEVA is $\sim 70.0 \div 110 \mathrm{~mm}$ for a period of 8 to 9 days.

By not estimating correctly the tropospheric delay - especially in the case of no mapping when the wet delay was not estimated, this unmodeled parameter it is absorbed by the carrier phase residuals, hence generating large variations of the station position on horizontal and vertical component. Another explanation of the position variation when no mapping function was used, is that unmodeled tropospheric delay and estimated ambiguity is absorbed into the receiver clock, thus generating position variation. In our case the rule of thumb is more $1 / 4$ when using the VMF1 and GMF/GPT2 and to $1 / 5$ when using NMF.

Using the PPP technique among other parameters, we can determine the coordinates of the stations, from which we can determine the length between the stations. The problem of the coordinate variation is that the changes will be reflected on the distance between the respective stations and on the repeatability of the length between those stations. Variation in the coordinates related to the changes of the cutoff elevation angle, is a good measure for the absolute accuracy of the mapping function, because the presence of a systematic error in the mapping function will change the baseline length when the cutoff angle is changed (Boehm and Schuh, 2004).

\subsection{EVALUATION OF COORDINATES REPEATABILITY -}

We will continue with the analysis of the repeatability for each component: North, East and Up. The standard deviation (SD) serves as a measure of repeatability. The coordinate repeatability is computed for each solution using different MF as a sqrt of sigma of the position time series of daily position. The results 


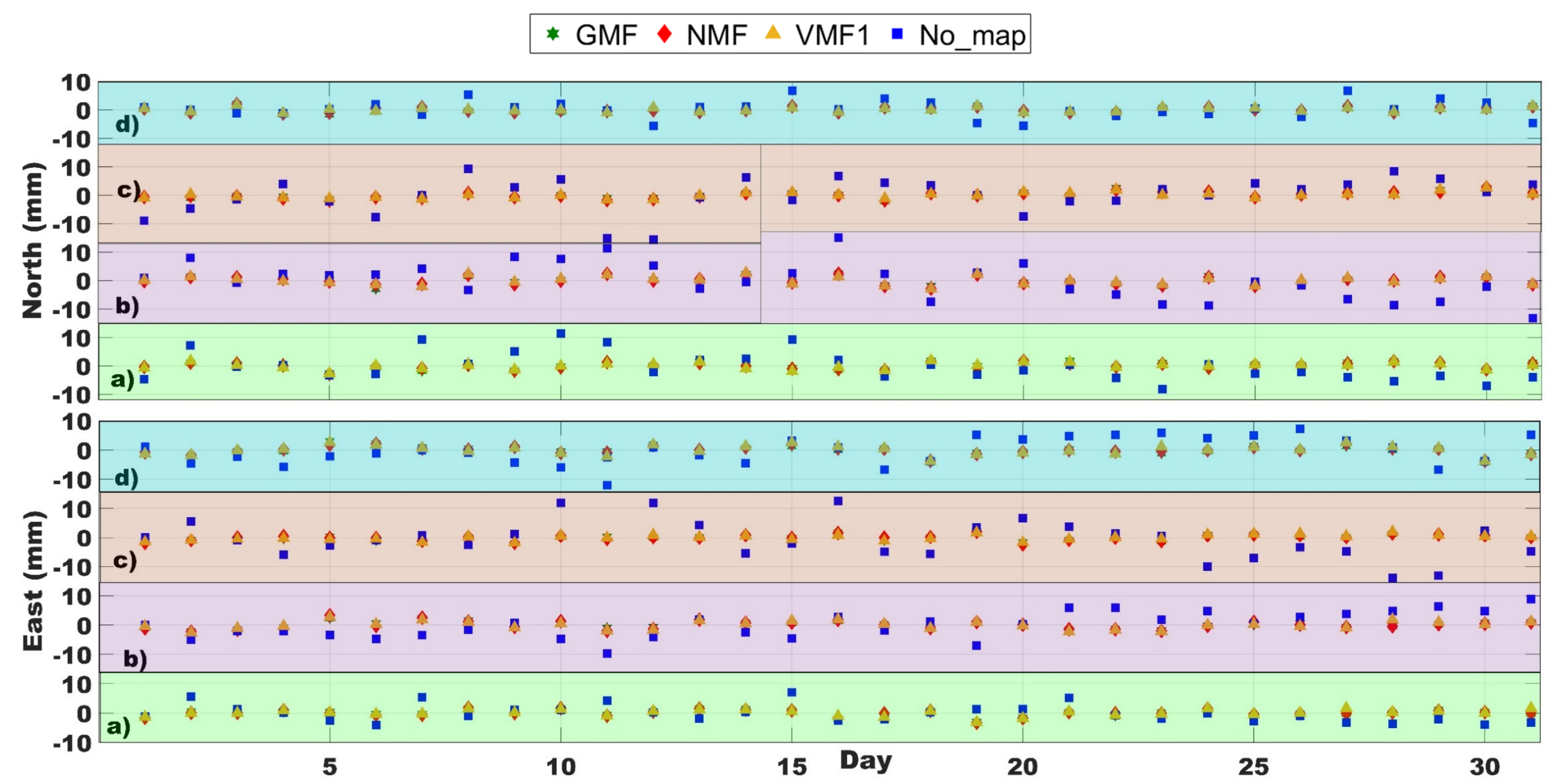

Fig. 5 Daily variability for the North and East component using different MF at $5^{0}$ elevation cutoff angle. a) station BACA - the green frame; b) station BAIA - the light magenta frame; c) station COST - the orange frame and d) station DEVA - the blue frame. 


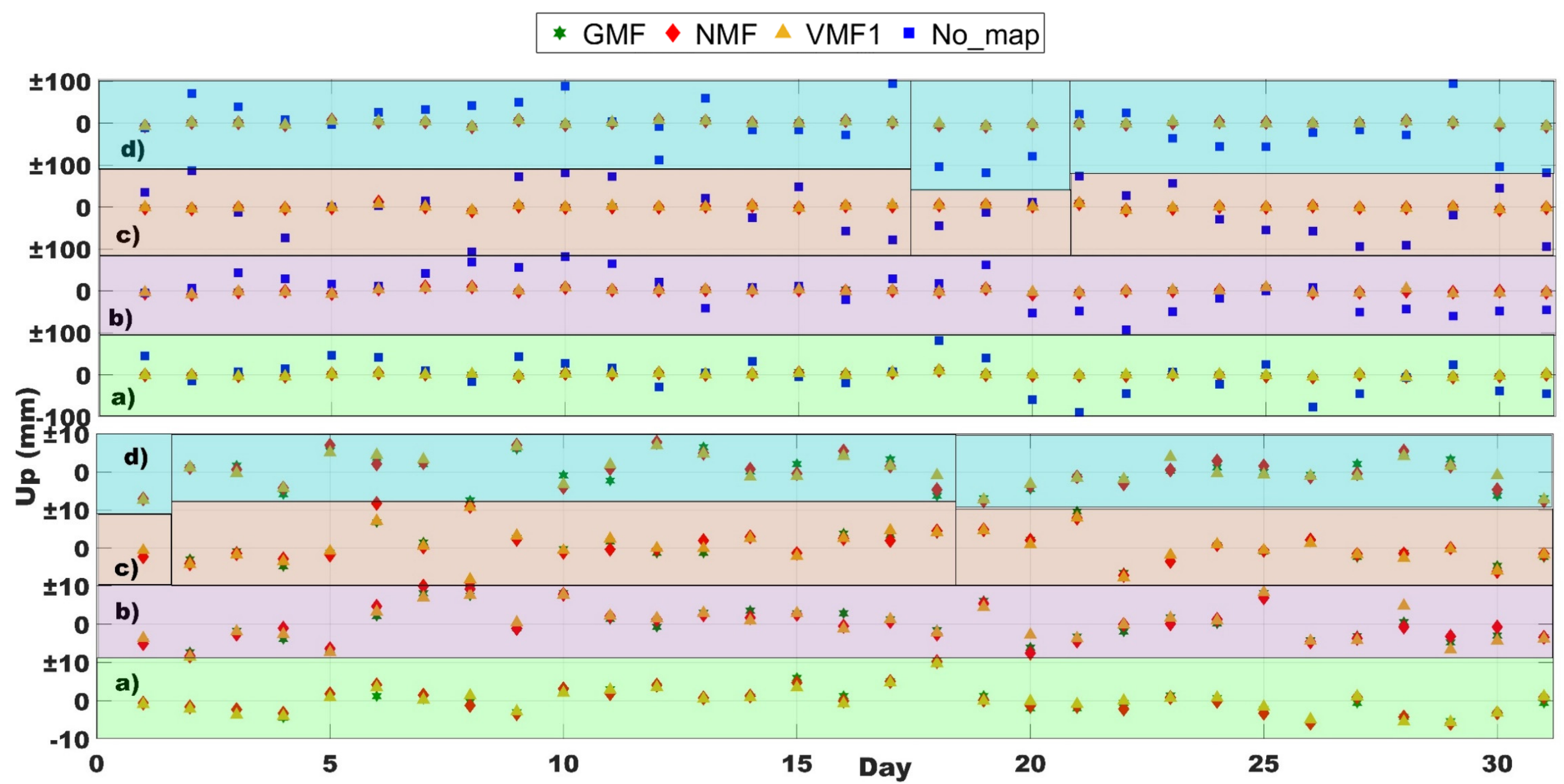

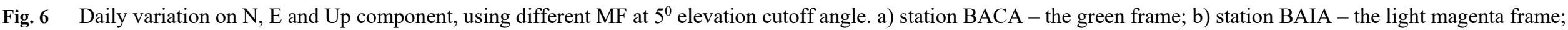
c) station COST - the orange frame and d) station DEVA - the blue frame 
Table 3 Coordinates repeatability when using different MF and different elevation cutoff angles for the North, East and Up component.

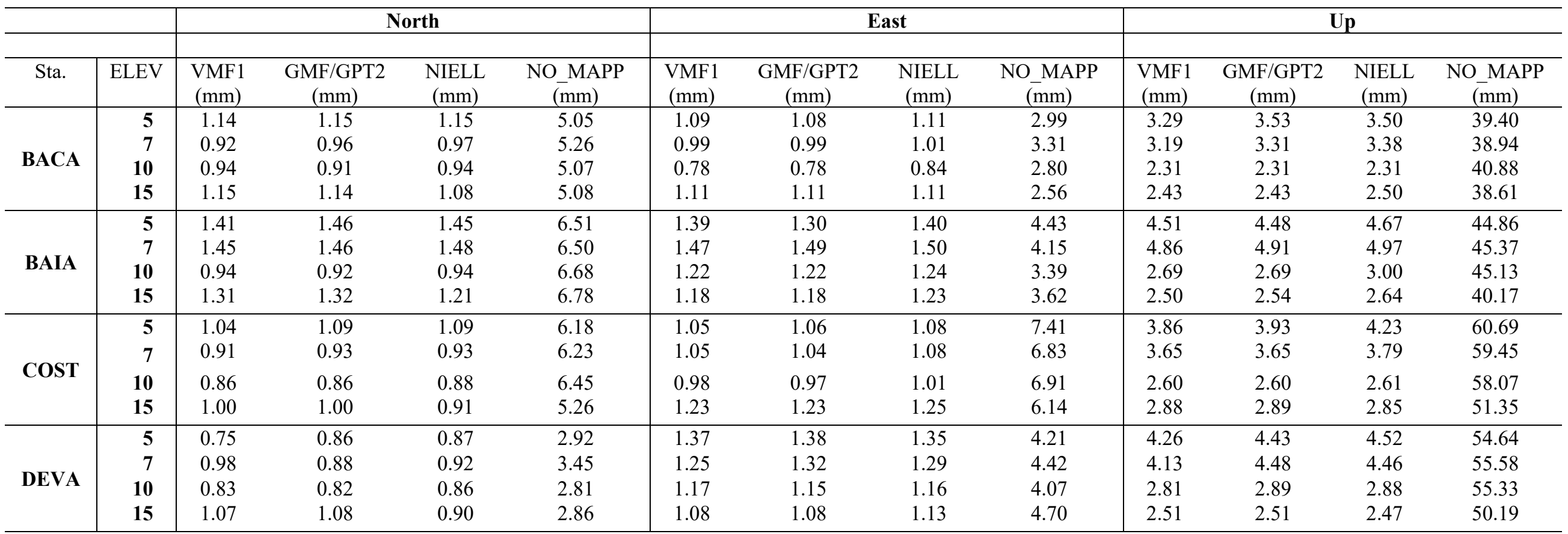

Table 4 Mean position repeatability of all the GNSS stations at different cut off elevation angle for the North, East and Up component.

\begin{tabular}{|c|c|c|c|c|c|c|c|c|c|c|c|c|}
\hline & \multicolumn{4}{|c|}{ North } & \multicolumn{4}{|c|}{ East } & \multicolumn{4}{|c|}{ Up } \\
\hline ELEV & $\begin{array}{l}\text { VMF1 } \\
(\mathrm{mm})\end{array}$ & $\begin{array}{c}\text { GMF/GPT2 } \\
(\mathrm{mm})\end{array}$ & $\begin{array}{l}\text { NIELL } \\
(\mathrm{mm})\end{array}$ & $\begin{array}{c}\text { NO_MAPP } \\
\text { (mm) }\end{array}$ & $\begin{array}{l}\text { VMF1 } \\
(\mathrm{mm})\end{array}$ & $\begin{array}{c}\text { GMF/GPT2 } \\
(\mathrm{mm})\end{array}$ & $\begin{array}{l}\text { NIELL } \\
(\mathrm{mm})\end{array}$ & $\begin{array}{c}\text { NO_MAPP } \\
(\mathrm{mm})\end{array}$ & $\begin{array}{l}\text { VMF1 } \\
(\mathrm{mm})\end{array}$ & $\begin{array}{c}\text { GMF/GPT2 } \\
(\mathrm{mm})\end{array}$ & $\begin{array}{c}\text { NIELL } \\
(\mathrm{mm})\end{array}$ & $\begin{array}{c}\text { NO_MAPP } \\
(\mathrm{mm})\end{array}$ \\
\hline 5 & 1.09 & 1.14 & 1.14 & 5.17 & 1.23 & 1.21 & 1.24 & 4.76 & 3.98 & 4.09 & 4.23 & 49.90 \\
\hline 7 & 1.07 & 1.06 & 1.08 & 5.36 & 1.19 & 1.21 & 1.22 & 4.68 & 3.96 & 4.09 & 4.15 & 49.84 \\
\hline 10 & 0.89 & 0.88 & 0.91 & 5.25 & 1.04 & 1.03 & 1.06 & 4.29 & 2.60 & 2.62 & 2.70 & 49.85 \\
\hline 15 & 1.13 & 1.14 & 1.03 & 5.00 & 1.15 & 1.15 & 1.18 & 4.26 & 2.58 & 2.59 & 2.62 & 45.08 \\
\hline
\end{tabular}


are presented in Table 3. The mean position repeatability for all the GNSS stations at different cut off elevation angle is presented in Table 4.

In Table 3 it can be observed that in all the components - North, East and Up, when no mapping function was used, the SD had a high value. For the horizontal components, the repeatability in the no mapping case is around 5 time worst whereas for the Up component is around 20 times.

The smallest SD for the North component at $5^{0}$ and $7^{0}$ is given by the VMF1, except station DEVA where at $7^{0} \mathrm{GMF} / \mathrm{GPT} 2$ gives the smallest SD. At $10^{0}$ the GMF/GPT2 presents the smallest SD and at $15^{\circ}$ is Niell mapping function.

The East component is more precise than the North component on all elevation cutoff angles. Also, the standard deviation (SD) between three MF, have closer results to each other, compared to North component.

Although there is a difference in SD when using the VMF1, GMF/GPT2 and Niell mapping function and on different elevation cutoff angles, this difference for the North component is at the level of $\sim 0.01 \div$ $0.18 \mathrm{~mm}$ and for the East component is $\sim 0.01 \div$ $0.10 \mathrm{~mm}$.

At $10^{0}$ we obtain the smallest SD for the three MF on the horizontal component except for the East component where the stations BAIA and DEVA have a better repeatability at $15^{\circ}$ elevation.

The Up component is much more sensitive to the tropospheric estimation than the horizontal components, thus we can see more daily variation and also bigger differences in terms of repeatability. For the Up component in all the elevation cutoff angle, compared to GMF/GPT2 and NMF, the VMF1 performs better, especially on low elevation - at $5^{0}$ and $7^{0}$. The SD from using NMF especially on $5^{0}$ and $7^{0}$ has higher values compared to the results by using GMF/GPT2 and VMF1. At $10^{\circ}$ and $15^{\circ}$ cutoff elevation angle all three MF presents similar performance, except station BAIA at $10^{\circ}$, when NMF has a difference compared to VMF1 of $0.31 \mathrm{~mm}$.

The low SD of the VMF1 at $5^{0}$ and $7^{0}$, especially compared to NMF, are in accordance with the results found by (Boehm and Schuh, 2004).

The mean position repeatability of the stations at different cut off elevation angles are presented in Table 4. It can be seen that the repeatability is more precise at $10^{\circ}$ compared with the cutoff elevation angle of $5^{0}$ and $7^{0}$ on the North component of about $17 \%$ and $\sim 22 \%$ compared to $15^{\circ}$. On the East component the smallest SD is the same as for the North component, at $10^{\circ}$, but the improvement is at the level of $\sim 13 \%$ compared to $5^{0}$ and $7^{0}$ cutoff elevation angle, whereas compared to $15^{0}$ is at the level of $\sim 10 \%$.

For the Up component, the repeatability is more precise on $10^{\circ}$ and $15^{\circ}$ but with very small difference compared to each other. The repeatability is more precise at $10^{0}$ compared to $5^{0}$ and $7^{0}$ cutoff elevation angle and it is at the level of $\sim 35 \%$ better for all three MF - GMF/GPT2, NMF and VMF1.

\section{DISCUSSION AND CONCLUSIONS}

In this article we have analyzed 4 EUREF GNSS stations using the PPP technique embodied in the JPL - GIPSY-OASIS software. The effect of using different types of mapping functions such as: Niell, GMF/GPT2 and VMF1, to study the effect on LC and $\mathrm{PC}$ postfit residuals is presented. The research is continued on analyzing the daily variability of the coordinates and their repeatability.

The lowest values for the LC postfit residuals are given by the VMF1, but very similar results are also triggered by using GMF/GPT2. The two MF are in agreement, especially above $10^{\circ}$ elevation cutoff angle, whereas the NMF is converging to the VMF1 and GMF/GPT2 results especially above $15^{\circ}$. By using the weighting scheme, the low elevation observation are downweighed properly and the distribution of postfit residuals is more stable, results confirmed also by (Kačmařík et al., 2019).

The distribution of the LC postfit residuals with respect to the elevation angle, for the station BACA is much smoother after $20^{\circ}$, whereas for station BAIA is only after $40^{\circ}$. In the case of station BACA compared to BAIA, the NMF is not able to produce a smoother spread of the LC postfit residuals compared to VMF1 only after $40^{\circ} \sim 50^{\circ}$.

It is clear that the VMF1 performs better than GMF/GPT2 and NMF at elevation below the $10^{\circ}$ whereas for elevation above $10^{\circ}$ the three MF have relatively similar performance, results found also by (Qiu et al., 2020).

Although the PC combination on the no mapping strategy for the station BACA and BAIA had the lowest values of the postfit residuals, whereas station COST and DEVA had the highest values of the postfit residuals, the differences between the MF are at the level of $0.02 \div 0.25 \mathrm{~cm}$.

We can draw the conclusion that an appropriate mapping function is able to improve the LC postfit residuals, thus improving the station coordinates and their daily variability using different elevation cutoff angles.

In terms of differences between each individual daily solution in the horizontal component, the VMF1 and GMF/GPT2 strongly agree, whereas by using $\mathrm{NMF}$, resulted in differences at the submillimeter level with extreme values of $\sim 1.0 \mathrm{~mm}$ in 5 to 6 days. The Up component is more receptive to changes in the troposphere and the daily differences between each individual solution is at the level of $\sim 1.0 \div 1.5 \mathrm{~mm}$ with extreme values at the level of $\sim 2.2 \mathrm{~mm}$ for 6 to 10 days.

It should be noted that by using a longer time span - more than one month and sites with higher difference on latitude, longitude and height, could generate different results.

It can be seen from Figure 5 and 6 - in the no mapping case, that the daily differences between each individual solution is very high. This can be generated by the unmodeled tropospheric delay which is absorbed by the carrier phase residuals, hence 
generating large variations of the station position on the horizontal and vertical component

The performance of the MF has a strong dependence of the site location and height, due to the fact that the signal at low elevation has to pass a thicker part of the troposphere with the possibility of encountering larger quantity of the water vapor, thus making more difficult for the mapping function to accurately model the relationship between the zenith direction and slant direction.

Low elevation observations $3^{0} \leq e \leq 15^{0}$ are essential to improve the accuracy of GNSS positioning especially to decorrelate the estimated station heights and the tropospheric zenith total delays (Zhou et al., 2017). Although low elevation observations induce data with higher noise, as can be seen from Figure 3, but using a proper elevation-dependent weighting scheme, this data can be properly downweighed, so that the station height is not affected by the low elevation observation data.

We can see that different MF produce different LC postfit residuals, but also different coordinate estimates, not only in terms of daily variability, but also in terms of precision, thus we have to pay attention on which MF is used during estimation, because this final estimate can significantly influence when a new terrestrial reference frame is developed. The daily variability of coordinates and their repeatability has higher difference from elevation between $5^{0}$ to $10^{0}$, whereas above $10^{0}$ the three MF tends to presents very similar results.

From Tables 3 and 4 the position repeatability at $10^{0}$ cutoff elevation angle presents the smallest SD on the horizontal component, but the North component is improving with $\sim 3 \div 4 \%$ more than the East component, when we change the cutoff elevation angle from $5^{0}$ to $10^{\circ}$.

For the Up component the changes of the cutoff elevation angle from $5^{0}$ to $10^{0}$ presents an improvement of the repeatability of roughly $\sim 35 \%$.

The results show that the stations have a worse repeatability at $5^{0}$ on North, East and Up component and starts decreasing with the elevation cutoff angle until $10^{\circ}$, which shows the smallest SD and starts to increase towards $15^{\circ}$ elevation cutoff angle. From our study we can conclude that the positioning performance in terms of repeatability is best achieved at cutoff elevation angle of $10^{\circ}$ and using the VMF1, which is on accordance with the findings of (Kačmařík et al., 2017; Zhou et al., 2017) who concluded based on their study that the positioning performance is at elevation cutoff angles of $7^{0}$ or $10^{\circ}$. Although the VMF1 presents better results that GMF/GPT2 and NMF, the downside is that VMF1 implements a more sophisticated modelling approach by using the external data from ECMWF. The results from GMF/GPT2 strongly agrees with VMF1 especially above $10^{\circ}$, but the dependence of external data is overpassed, which is the reason way GMF/GPT2 is a suitable backup. With the new developments of GPT2w (Böhm et al., 2015) or GPT3 (Landskron and
Böhm, 2018) which have an improved resolution of $1^{0} \times 1^{0}$ it is possible that the agreement in terms of position repeatability between the VMF1 and GPT $2 \mathrm{w}$ or GPT3 to improve over lower elevation angle.

\section{ACKNOWLEDGMENTS}

We would like to thank the two anonymous reviewers and editor who provided numerous suggestions and comments that significantly improved the manuscript.

\section{REFERENCES}

Azúa, B.M., DeMets, C. and Masterlark, T.: 2002, Strong interseismic coupling, fault afterslip, and viscoelastic flow before and after the Oct. 9, 1995 Colima-Jalisco earthquake: Continuous GPS measurements from Colima, Mexico. Geophys. Res. Lett., 29, 8, 122-124. DOI: 10.1029/2002GL014702

Bevis, M., Businger, S., Herring, T., Rocken, Ch., Anthes, R., and Ware, R.: 1992, GPS meteorology: Remote sensing of atmospheric water vapor using the global positioning system. J. Geophys. Res., 97, D14, 15787. DOI: 10.1029/92JD01517

Blewitt, G.: 1989, Carrier phase ambiguity resolution for the Global Positioning System applied to geodetic baselines up to $2000 \mathrm{~km}$. J. Geophys. Res., Solid Earth. Res., 94, B8, 10187-10203.

DOI: 10.1029/JB094iB08p10187

Boehm, J., Niell, A., Tregoning, P. and Schuh, H. : 2006b, Global Mapping Function (GMF): A new empirical mapping function based on numerical weather model data. Geophys. Res. Lett., 33, 7, L07304.

DOI: $10.1029 / 2005$ GL025546

Boehm, J. and Schuh, H.: 2004, Vienna mapping functions in VLBI analyses. Geophys. Res. Lett., 31, 1. DOI: $10.1029 / 2003$ GL018984

Boehm, J., Werl, B. and Schuh, H.: 2006a, Troposphere mapping functions for GPS and very long baseline interferometry from European Centre for MediumRange Weather Forecasts operational analysis data. J. Geophys. Res., 111, B2, B02406. DOI: $10.1029 / 2005 J B 003629$

Böhm, J., Möller, G., Schindelegger, M., Pain, G. and Weber, R.: 2015, Development of an improved empirical model for slant delays in the troposphere (GPT2w). GPS Solut., 19, 3, 433-441.

DOI: 10.1007/s10291-014-0403-7

Dach, R. , Hugentobler, U., Fridez, P. and Meindl, M.: 2007, Bernese GPS software version 5.0. Astronomical Institute, University of Bern, 640, 114.

Dee, D.P., Uppala, S.M., Simmons, A.J. et al. : 2011, The ERA-Interim reanalysis: configuration and performance of the data assimilation system. Q. J. R. Meteorol. Soc., 137, 656, 553-597. DOI: $10.1002 /$ aj. 828

Dodson, A.H., Shardlow, P.J., Hubbard, L.C.M., Elgered, G. and Jarlemark, P.O.J.: 1996, Wet tropospheric effects on precise relative GPS height determination. J. Geod., 70, 4, 188-202. DOI: 10.1007/BF00873700

Douša, J.: 2009, The impact of errors in predicted GPS orbits on zenith troposphere delay estimation. GPS Solut., 14, 3, 229-239. DOI: 10.1007/s10291-009-0138-z

Hammond, W.C.: 2005, Northwest basin and range tectonic deformation observed with the Global Positioning System, 1999-2003. J. Geophys. Res., 110, B10, B10405. DOI: 10.1029/2005JB003678 
Héroux, P. and Kouba, J.: 2001, GPS precise point positioning using IGS orbit products. Phys. Chem. Earth, Part A: Solid Earth and Geodesy, 26, 6, 573578. DOI: 10.1016/S1464-1895(01)00103-X

Jin, S. and Komjathy, A.: 2010, GNSS reflectometry and remote sensing: New objectives and results. Adv. Space Res., 46, 2, 111-117. DOI: $10.1016 / \mathrm{j}$.asr.2010.01.014

Kačmařík, M., Douša, J., Dick, G. et al.: 2017, Intertechnique validation of tropospheric slant total delays. Atmos. Meas. Tech., 10, 6, 2183-2208. DOI: $10.5194 / \mathrm{amt}-10-2183-2017$

Kačmařík, M., Douša, J., Zus, F. et al.: 2019, Sensitivity of GNSS tropospheric gradients to processing options. Ann. Geophys., 37, 3, 429-446. DOI: 10.5194/angeo-37-429-2019

King. M. and Aoki, S.: 2003, Tidal observations on floating ice using a single GPS receiver. Geophys. Res. Lett., 30, 3, 1138. DOI: 10.1029/2002GL016182

Kouba, J.: 2008, Implementation and testing of the gridded Vienna Mapping Function 1 (VMF1). J. Geod., 82, 45, 193-205. DOI: 10.1007/s00190-007-0170-0

Kouba, J.: 2009, Testing of global pressure/temperature (GPT) model and global mapping function (GMF) in GPS analyses. J. Geod., 83, 3-4, 199-208. DOI: $10.1007 / \mathrm{s} 00190-008-0229-6$

Lagler, K., Schindelegger, M., Böhm, J., Krásná, H. and Nilsson, T.: 2013, GPT2: Empirical slant delay model for radio space geodetic techniques. Geophys. Res. Lett., 40, 6, 1069-1073. DOI: 10.1002/grl.50288

Landskron, D. and Böhm, J.: 2018, VMF3/GPT3: refined discrete and empirical troposphere mapping functions. J. Geod., 92, 4, 349-360.

DOI: $10.1007 / \mathrm{s} 00190-017-1066-2$

Maciuk, K.: 2019, Monitoring of Galileo on-board oscillators variations, disturbances and noises. Measurement, 147, 106843.

DOI: 10.1016/j.measurement.2019.07.071

Maciuk, K. and Lewinska, P.: 2019, High-rate monitoring of satellite clocks using two methods of averaging time. Remote Sens., 11, 23, 2754. DOI: $10.3390 /$ rs 11232754

Maciuk, K. and Szombara, S.: 2018, Annual crustal deformation based on GNSS observations between 1996 and 2016. Arab. J. Geosci., 11, 21, 667. DOI: $10.1007 / \mathrm{s} 12517-018-4022-4$

Nastase, E.I., Muntean A., Nistor, S., Grecu, B. and Tataru D.: 2020, GPS processing tool for better impact assessment of earthquakes in Romania. Rom. Rep. Phys., 72, 2, 707.

Niell, A.E.: 1996, Global mapping functions for the atmosphere delay at radio wavelengths. J. Geophys. Res., 101, B2, 3227-3246. DOI: 10.1029/95jb03048

Nistor, S. and Buda, A.S.: 2015, Using different mapping function in GPS processing for remote sensing the atmosphere. J. Appl. Eng. Sci., 5, 2, 73-80. DOI: $10.1515 /$ jaes-2015-0024

Nistor, S. and Buda, A.S.: 2016a, GPS network noise analysis: a case study of data collected over an 18 month period. J. Spat. Sci., 61, 2, 427-440. DOI: $10.1080 / 14498596.2016 .1138900$

Nistor, S. and Buda, A.S.: 2016b, The influence of different types of noise on the velocity uncertainties in GPS time series analysis. Acta Geodyn. Geomater., 13, 4, 387-394. DOI: 10.13168/AGG.2016.0021

Nistor, S. and Buda, A.S.: 2017, Evaluation of the ambiguity resolution and data products from different analysis centers on zenith wet delay using PPP method. Acta Geodyn. Geomater., 14, 2, 205-220. DOI: 10.13168/AGG.2017.0004

Qiu, C., Wang, X., Li, Z. et al. : 2020, The performance of different mapping functions and gradient models in the determination of slant tropospheric delay. Remote Sens., 12, 1, 130. DOI: 10.3390/rs12010130

Saastamoinen, J.: 1973, Contributions to the theory of atmospheric refraction. Bull. Géod., 107, 1, 13-34. DOI: $10.1007 / \mathrm{BF} 0252208$

Shi, C., Lou, Y., Zhang, H. et al.: 2010, Seismic deformation of the Mw 8.0 Wenchuan earthquake from high-rate GPS observations. Adv. Space Res., 46, 2, 228-235. DOI: 10.1016/j.asr.2010.03.006

Shi, C., Zhao, Q., Geng, J. et al.: 2008, Recent development of PANDA software in GNSS data processing. Proc. SPIE, 7285. DOI: $10.1117 / 12.816261$

Suba, N.S., Nistor, S. and Suba, Șt.: 2017, Effects of DEM generating algorithms on water retention calculations in Polders - A case study. J. Appl. Eng. Sci., 7, 2, $63-$ 68. DOI: $10.1515 /$ jaes-2017-0015

Takasu, T. and Yasuda, A.: 2009, Development of the lowcost RTK-GPS receiver w.th an open source program package RTKLIB. International symposium on GPS/GNSS. International Convention Center, Jeju, Korea, 4-6.

Tregoning, P. and Herring, T. A.: 2006, Impact of a priori zenith hydrostatic delay errors on GPS estimates of station heights and zenith total delays. Geophys. Res. Lett., 33, 23, L23303. DOI: 10.1029/2006GL027706

Vaclavovic, P., Dousa, J. and Gyori, G.: 2013, G-Nut software library-state of development and first results. Acta Geodyn. Geomater., 10, 4, 431-436. DOI: $10.13168 /$ AGG.2013.0042

Wang, H., Wei, M., Li, G. et al.: : 2013, Analysis of precipitable water vapor from GPS measurements in Chengdu region: Distribution and evolution characteristics in autumn. Adv. Space Res., 52, 4, 656667. DOI: $10.1016 /$ j.asr.2013.04.005

Williams, S.D.P. and Nievinski, F.G.: 2017, Tropospheric delays in ground-based GNSS multipath reflectometry-Experimental evidence from coastal sites. J. Geophys. Res., Solid Earth, 122, 3, 2310 2327. DOI: $10.1002 / 2016 J B 013612$

Williams, S.D.P. and Willis, P.: 2006, Error analysis of weekly station coordinates in the DORIS network. J. Geod., 80, 8, 525-539. DOI: $10.1007 / \mathrm{s} 00190-006-0056-6$

Zhao, Q., Yao, Y., Yao, W., Li, Z.: 2018, Real-time precise point positioning-based zenith tropospheric delay for precipitation forecasting. Sci. Rep., 8, 1, 7939. DOI: $10.1038 / \mathrm{s} 41598-018-26299-3$

Zhou, F., Li, X., Li, W. et al.: 2017, The impact of estimating high-resolution tropospheric gradients on multi-GNSS precise positioning. Sensors, 17, 4, 756. DOI: $10.3390 / \mathrm{s} 17040756$

Zumberge, J.F., Heflin, M.B., Jefferson, D.C. et al.: 1997, Precise point positioning for the efficient and robust analysis of GPS data from large networks. J. Geophys. Res., 102, B3, 5005. DOI: 10.1029/96JB03860 